\title{
Temporal Multiscale Consumption Strategies of Intermittent Energy based on Parallel Computing
}

\author{
Huifen Chen ${ }^{\mathrm{a}}$, Yiming Zhang ${ }^{\mathrm{a}}$, Feng Yao ${ }^{\mathrm{a}}$, Zhice Yang ${ }^{\mathrm{b}, \mathrm{c}}$, Fang Liu ${ }^{\mathrm{b}, *}$, Yi Liu ${ }^{\mathrm{a}}$, Zhiheng Li ${ }^{\mathrm{a}}$, \\ and Jinggang Wang ${ }^{\mathrm{a}}$ \\ ${ }^{a}$ State Grid Henan Electric Power Company, Zhengzhou, 450052, China \\ ${ }^{b}$ Chinese Academy of Science, Beijing, 100190, China \\ ${ }^{c}$ University of Chinese Academy of Sciences, Beijing, 100049, China
}

\begin{abstract}
Fossil energy is non-renewable energy. The use of fossil energy power generation not only increases the consumption of energy, but also emissions will also bring environmental pollution. The resources of wind, light and other renewable energy are rich in China. The use of new energy power generation is conducive to energy security and sustainable development. Due to the characteristics of regional, intermittent, random and unpredictable of wind and light, large-scale wind power and photovoltaic power in national grid are seriously challenged by the overall dispatch of the power system. Firstly, the paper analyzes and improves the evaluation model of intermittent energy generation capacity by analyzing and processing the real data of a province Power Network. In the model, the photovoltaic unit output constraint and the pumped storage unit constraint of pumping stage and drawing-off stage and the storage capacity of pumped storage power station are added. Secondly, the input data of a province Power Network, which is in accordance with the input condition, is input into the proposed optimization model and the results are credible. In addition, the input data and output results are displayed in visualization formed by graphs, which provides effective guidance to the management of a province Power Network.
\end{abstract}

Keywords: intermittent energy generation; multi time-scale in monthly and yearly; photovoltaic unit model constraint; pumped storage unit model constraint

(Submitted on February 8, 2018; Revised on March 16, 2018; Accepted on April 23, 2018)

(C) 2018 Totem Publisher, Inc. All rights reserved.

\section{Introduction}

Energy problem is becoming more serious in China; the domestic coal consumption is growing at an annual rate of 120 to 200 million tons. The energy consumption and demand growth expand our energy gap further. It also brings serious environmental problems. At the same time, the resources in China are abundant and widely distributed, which distribution has certain complementary characteristics with water resources. However, the coordination problem between new energy penetration capability and the operation mode of the system has not been solved. In order to ensure the safe and stable operation of the power system, the power generation is severely restricted due to many factors such as the low peak, the ability of the cross section, the system current, the voltage, the power quality and so on. Researching large-scale long-term intermittent energy operation can fill in the blank of the new energy power generation's optimal operation and electricity support technology.

Based on the actual situation of the power grid in the certain province, this paper makes a statistical analysis based on the time series, the evaluation model of the existing power grid [1,5,7] and input and output data. The provincial power grid electricity load, scenery power generation theory predicts, the association of foreign provinces and link transmission power, and the power positive rotation reserve are adjusted for the models.

\footnotetext{
* Corresponding author.

E-mail address: liufang@sccas.cn
} 


\section{Balmorel Model}

At present, research on wind power operation optimization mainly focuses on the following aspects: 1) influence of uncertainty on the operation mode of the conventional unit of the power system after wind power is connected to the network [10,15]; 2) consider the conventional unit scheduling strategy for intermittent energy forecasting errors [6]; 3) combined operation system of wind, photovoltaic energy and energy storage can be used in combination operation system to study [2]; 4) research on the optimization algorithm of large-scale stochastic wind power optimization [4] has achieved some results.

China's wind power industry is developing rapidly. From 2006 to 2013, the intermittent energy power supply has doubled in the past seven years, and the intermittent energy generating capacity is bigger than that of the major provinces, which system's peak, frequency modulation and pressure adjustment have been under great pressure [8]. As of now, the short-term and ultra-short-term wind power forecasting system has been established in various networks and provinces, and it has some guidance and reference for the operation of the system. Domestic scholars have carried out the research on the assessment of the long-term acceptance capacity of wind power generation, and obtained some results, which are mainly used to guide planning problems [17,18]. However, wind power, about the guidance system of annual and monthly midterm optimal operation research, is still in its early stages. In-depth study of the problem needs to be conducted to guide the operation of power system. Many domestic scholars made a lot of related research. For example, Prof. Tong with his research on smart grid security risk constraint multistage stochastic optimization problem of economic operation risk research based on the Worst Case conditions as an index, hypothesis and ellipsoid distribution of random variables. He set up a two stage Worst - Case risk profit optimization model [3,20], and used Monte Carlo point method to numerical simulation of the random variable power market asset allocation problem is studied. Prof. Guo did some research of distributed power (wind, solar, etc.) to access the placement of the locations of the smart grid and the circuit breaker. He established a multi-objective optimization model to minimize the distributed power installation cost and transport cost. He also considered the reliability of micro network distributed power placement strategy problem and $0-1$ mixed integer programming model is established [11]. For mixed integer programming, Prof. Sun focused on mixed integer bounds [12], series system [13] and complex system [9], quadratic programming [19] and continuous variable problems [14].

The method of simulating the acceptance ability of grid is widely accepted by the industry. Abroad studies of the accept ability of wind power gradually form an analytic tool of simulation. For example, they develop a universal model of electric power production simulation in Denmark called the Balmorel model. This model can contain new energy power system for production process simulation, which can analyze all kinds of power source of economy development and power optimization plan. Development of Balmorel model is applied to the analysis of energy, which is related to economic and policy issues in the system, specially focusing on electric power system and power plant system technical analysis. We need to find economic and efficient scheduling and plan of capacity's expansion for the current energy system.

Based on the secondary development of intermittent energy acceptance model, we set up a comprehensive evaluation method to determine regional power grid and key nodes' acceptance of wind power. By predicting the electricity grid data of a province of northeast China in 2015 and comparing the data in 2014, the model is correct.

The optimization of new energy production simulation is a large-scale mixed integer programming problem. Its goal is to maximize the new energy output, which includes wind power and photovoltaic power. The formula shown as Equation (1):

$$
\max \sum_{t=1}^{T} \sum_{n=1}^{N} C_{1} n e w e n e r g y(t, n)-C_{2}\left(\sum_{j=1}^{S_{k i n d}} A_{j} S_{j, o n}^{t, n}+B_{j} S_{j, \text { off }}^{t, n}+C P_{j}^{t, n}\right)-C_{3} \sum_{j=1}^{S_{k i n d}}\left|S_{j}(t, n)-S_{j}(t-1, n)\right|
$$

$\mathrm{N}$ represents the number of areas. $\mathrm{T}$ represents the time in simulation. Newenergy $(\mathrm{t}, \mathrm{n})$ represents new energy power output, $C_{1}, C_{2}, C_{3}$ are weight coefficient; $A_{j}$ is rev machine coal consumption, $B_{j}$ is stop coal consumption. $C$ is coal consumption constant. $S_{j}(t, n)$ represents the number of open unit at $n$ area at $t$ time. $S_{j, \text { on }}$ represents the change of open units, $S_{\mathrm{j}, \text { off }}$ represents the change of close units.

\section{Model Verification and Analysis}

In recent years, the provincial power load steady growth, and annual growth rate has been more than 5\%. However, the grid peak valley rate is increasing year by year, which makes it difficult to control the power grid operation and make the safety of power grid operation decrease year by year. The province electric heating unit installed is more than $70 \%$ in all capacities. 
Over the winter period, the capacity of peak load regulation has fallen sharply. "Keep High Peak" and "pressure trough" are two big difficulties. Low load in power system becomes the main factor of clean energy, which is given in the province power grid.

In order to make better use of the actual data of the provincial power grid as a follow-up modeling service, the original grid load data has been graphically displayed and analyzed. There are two main statistics.

User power load distribution is shown in Figure 1, which is based on the year 8736 hours of power load of the histogram statistics. It can be seen from the graph that users maximum peak often occurs in the summer. The maximum occurs in the autumn winter season, which keeps a steady power level. The minimum power load of the system appears in the first day of the fifth week, when Chinese Lunar New Year is affected by the holiday and the return of people going back home. During that time, the electricity load is low. $\mathrm{N}_{1}, \mathrm{~N}_{2}$ and $\mathrm{N}_{3}$ represent the three areas of the province.

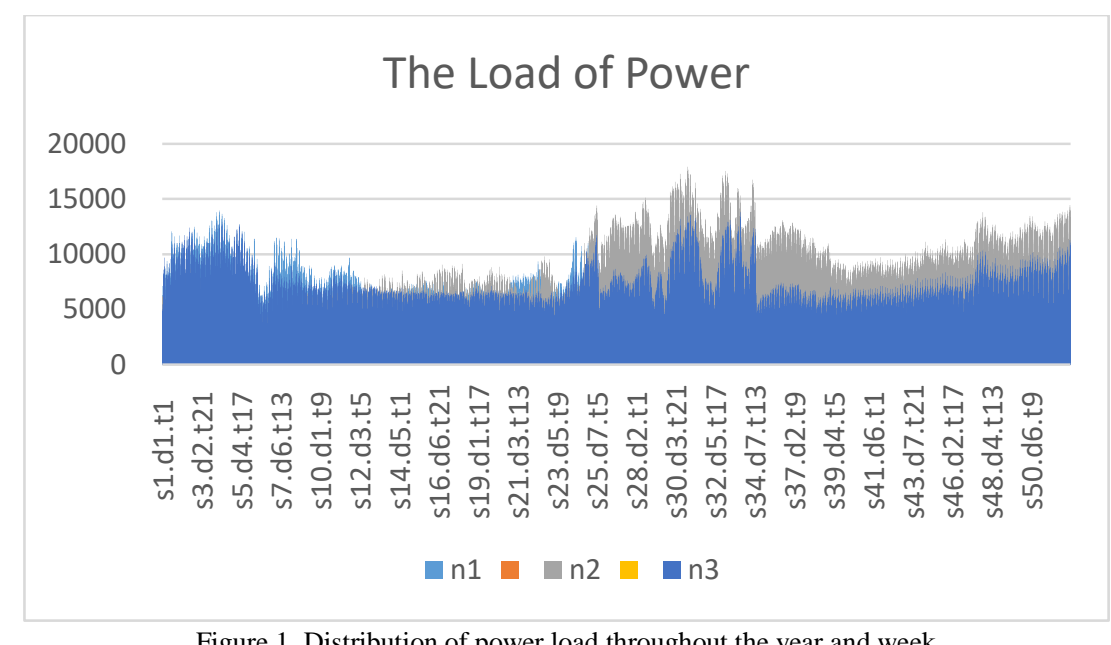

Figure 1. Distribution of power load throughout the year and week

The intermittent energy acceptance assessment model is processed into 44 input documents, which are divided into three main categories:

(1) The parameter settings of the grid unit in some province of China (29 files): conventional units, pumped storage power units and new energy power unit and the installed capacity of wind and photovoltaic turbine, regular climbing and downhilling information of each power unit.

(2) Basic setting of model time series (7 files): divide a year by week, day and hour, and iteration by week.

(3) Setting of the property of a power plant in the province (8 files): power exchange data with foreign provinces, power grid prediction power, standby capacity and partition information of power grid. By setting the above three types of parameters, the specific data of the provincial power grid power plant can be compiled into basic model input. The input data of the model is shown in Table 1, where the conventional unit parameters can be set to 24 variables in a total of 4 classes.

Table 1. Descriptions of the input data of the model

\begin{tabular}{|l|l|l|}
\hline Variable & Description & Format \\
\hline Load & Regional power load & matrix \\
\hline TheoryWindpower & Theory Wind power & matrix \\
\hline TheoryPVpower & Theory Photovoltaic power & matrix \\
\hline TranP & Power of outgoing contact line & matrix \\
\hline Pres & Positive reserve capacity & numerical \\
\hline Winderr & Wind power error & numerical(percentage) \\
\hline PVerr & Photovoltaic power error & numerical(percentage) \\
\hline N & Simulation area number & numerical \\
\hline onmax & The maximum number of downtime of the system cycle & matrix \\
\hline Windcap & Regional wind power capacity & matrix \\
\hline PVcap & Regional Photovoltaic power capacity & matrix \\
\hline Basic information & Basic information of the normal unit & matrix \\
\hline
\end{tabular}


The two input parameters of the one-week photovoltaic power and one-week wind power output are analyzed. Figure 2 shows the percentage line of power of the first week; maximum value of photoelectric output is reached at 13:00. From 16:00 to 7:00, the photoelectric theory is 0 . Photovoltaic power is intermittent. The stochastic and unpredictability of wind power can be obtained from the change curve. Further analysis concludes that wind power has the characteristics of reverse peak.

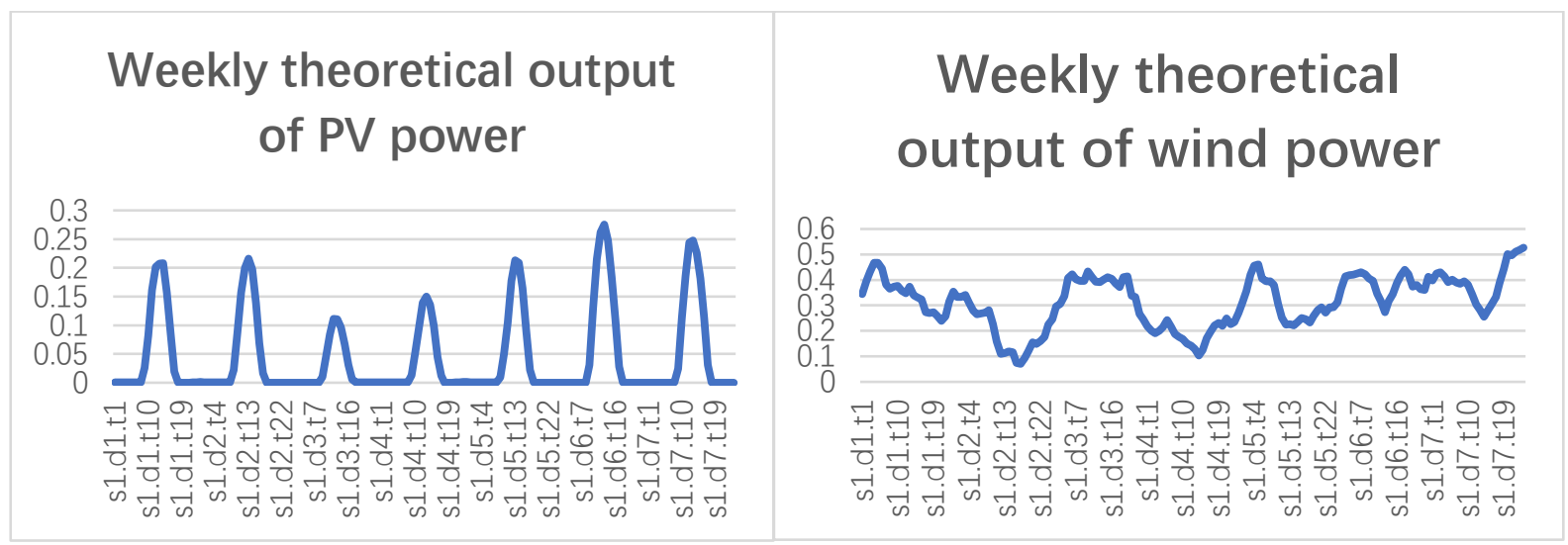

Figure 2. The first week of the landscape theory output percentage line chart of (a) PV (b) wind

This paper carries out multi-scale verification of the evaluation optimization model of intermittent energy generation capacity in the annual and monthly scales. Forecast the intermittent energy power of the province in the next two or three years.

The number of sets in the input data sets.inc is $\mathrm{s} 1 * \mathrm{~s} 52$, which is the time span of one year. The power of wind and photoelectric prediction is calculated according to the actual scene theory of 2016. The installation of intermittent energy installed capacity predicts the installed capacity in 2017. According to 2016 data, load capacity is on the basis of increased by 5\% for input, and to fine-tune the input data according to the Spring Festival (8 February 2016 for the lunar New Year holiday, January 28, 2017 for the Spring Festival, so we need to forward the data of 2016 circularly 11 days to ensure that the load is used to simulate authoritatively).

Take the annual input into the model to carry out the simulation, and get the output of the annual model. This is shown in Table 2.

Table 2. The annual model outputs

\begin{tabular}{|l|l|l|}
\hline Variable & Value & Description \\
\hline intwindgross & 2505883.14 & Total acceptance of wind power $(\mathrm{MW} \cdot \mathrm{h})$ \\
\hline intPVgross & 3310981.563 & Total acceptance of PV power $(\mathrm{MW} \cdot \mathrm{h})$ \\
\hline intnewenergygross & 5816864.703 & Total acceptance of new energy power $(\mathrm{MW} \cdot \mathrm{h})$ \\
\hline newenergyerrorgross & 0 & Total new energy limits $(\mathrm{MW} \cdot \mathrm{h})$ \\
\hline newenergyerrorrategross & $0 \%$ & Total new energy limits rate \\
\hline
\end{tabular}

New energy totally includes wind power generation and photovoltaic power generation, and its value is 5816864 $\mathrm{MW} \cdot \mathrm{h}$. There is no limit to power generation in the province.

The number of wind power and photovoltaic power in each area is shown in Table 3.

Table 3. The wind power and photovoltaic power in each area 1

\begin{tabular}{|l|l|l|l|}
\hline Power out $(105 \mathrm{MW} \cdot \mathrm{h})$ & $\mathrm{N}_{1}$ & $\mathrm{~N}_{2}$ & $\mathrm{~N}_{3}$ \\
\hline PV power & 2.293 & 12.738 & 10.028 \\
\hline Wind power & 12.397 & 6.857 & 13.856 \\
\hline
\end{tabular}

The number of sets.inc in the input data was changed to $\mathrm{s} 1 * \mathrm{~s} 13$, and the data model was optimized for 3 months in January, February and March. Adjust the tableEload.inc in the input data to the actual user load of January to March 2017. The actual theoretical output of the theory of wind power theory, tabletheorywind.inc and tabletheoryPV.inc, is adjusted to simulate the theoretical model from January to March 2017.

The monthly input into the model is simulated, and the monthly output of Table 4 is obtained. 
Table 4. The monthly model outputs

\begin{tabular}{|l|l|l|}
\hline Variable & Value & Description \\
\hline intwindgross & 574352.517 & Total acceptance of wind power $(\mathrm{MW} \cdot \mathrm{h})$ \\
\hline intPVgross & 634918.2966 & Total acceptance of PV power $(\mathrm{MW} \cdot \mathrm{h})$ \\
\hline intnewenergygross & 1209270.814 & Total acceptance of new energy power $(\mathrm{MW} \cdot \mathrm{h})$ \\
\hline newenergyerrorgross & 0 & Total new energy limits $(\mathrm{MW} \cdot \mathrm{h})$ \\
\hline newenergyerrorrategross & $0 \%$ & Total new energy limits rate \\
\hline
\end{tabular}

New energy in total including wind power generation and photovoltaic power generation, and its value is 1209270.814 $\mathrm{MW} \bullet \mathrm{h}$. The result is the current energy limited that does not exist in the province.

The number of wind power and photovoltaic power in each area is shown in Table 5.

Table 5. The wind power and photovoltaic power in each area 2

\begin{tabular}{|l|l|l|l|}
\hline Power out $(105 \mathrm{MW} \cdot \mathrm{h})$ & $\mathrm{N}_{1}$ & $\mathrm{~N}_{2}$ & $\mathrm{~N}_{3}$ \\
\hline PV power & 0.50 & 3.12 & 2.13 \\
\hline Wind power & 2.40 & 1.26 & 2.70 \\
\hline
\end{tabular}

The wind power of the province in 2017 will be $2520000 \mathrm{MW} \cdot \mathrm{h}$, while photovoltaic power will be $3310000 \mathrm{MW} \cdot \mathrm{h}$. By the calculation, wind power and photovoltaic power generation capacity can fix the load capacity in 2017, making no limit in intermittent energy power.

The back calculation of the first seven months in 2017 is shown in Table 6.

\begin{tabular}{|c|c|c|c|c|c|c|c|c|c|c|c|c|c|c|}
\hline Area & $105 \mathrm{MW} \cdot \mathrm{h}$ & Jan & Feb & Mar & Apr & May & Jun & Jul & Aug & Sep & Oct & Nov & Dec & All \\
\hline \multirow{2}{*}{$\mathrm{N}_{1}$} & simulate & 0.12 & 0.23 & 0.24 & 0.39 & 0.39 & 0.27 & 0.26 & 0.14 & 0.15 & 0.25 & 0.24 & 0.18 & 2.83 \\
\hline & real & 0.12 & 0.23 & 0.24 & 0.39 & 0.39 & 0.28 & 0.26 & - & - & - & - & - & - \\
\hline $\mathrm{N}_{2}$ & real & 1.07 & 1.16 & 0.79 & 0.91 & 0.88 & 0.52 & 0.69 & - & - & - & - & - & - \\
\hline \multirow{2}{*}{$\mathrm{N}_{3}$} & simulate & 0.71 & 0.88 & 0.59 & 0.99 & 1.109 & 0.66 & 1.25 & 0.35 & 0.55 & 0.88 & 0.95 & 1.05 & 9.97 \\
\hline & real & 0.71 & 0.88 & 0.59 & 0.99 & 1.10 & 0.66 & 1.24 & - & - & - & - & - & - \\
\hline
\end{tabular}

From the table above, we can see the simulation and the real data is match. The model's output is truthful.

Figure 3 shows the change of the number of two types of condensing units in the $\mathrm{N}_{3}$ region. The blue one represents $1030 \mathrm{MW}$ units and the orange one represents 645MW units. From the point of the curve, due to the principle of fossil power plant all open, at the beginning of the heating period (in figure is 46th weeks and 4th days), in the condensate gas unit will start more sets. In the 11th week on the 6th day to the end of the 20th week on the 4th day, due to the little load change, stopping small power units can meet the load demand. As for the end of the 24th week on 6th day to the 37th week on the 6th day, due to the heavy load changes, starting small power units cannot meet the load demand, so the 1030MW highpower units will also be started or closed. On the 5th day of the 46th week, the high-power unit will be given high priority. If the load is not enough, then the small power unit will be started to balance the load. This can reduce the energy consumption caused by the outage.

For the maintenance instruction, when the curve is smooth, the machine can be arranged for maintenance. The maintenance time needs to be satisfied until the next time there will be enough normal units which can be scheduled.

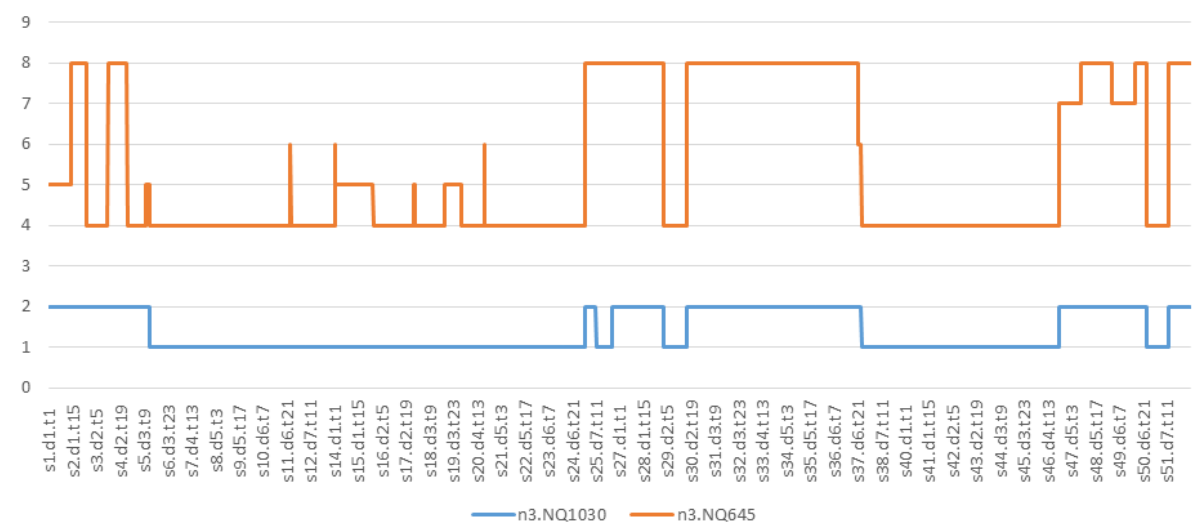

Figure 3. The number change of the condensate gas generator 
In 2017 , the total power consumption of the province will be approximately $2722 \sim 2858$ billion $\mathrm{KW} \cdot \mathrm{h}$, according to the average annual load increasing rete $0 \sim 5 \%$.

The sensitivity of limit photovoltaic and wind power in different load is shown in Table 7.

Table 7. The sensitivity in different load

\begin{tabular}{|c|c|c|c|c|c|c|c|c|c|c|}
\hline & \multicolumn{5}{|c|}{ Load power } & \multicolumn{5}{|c|}{ Result (\%) } \\
\hline & $\begin{array}{l}\text { increase } \\
1.2 \%\end{array}$ & $\begin{array}{l}\text { increase } \\
0 \%\end{array}$ & $\begin{array}{l}\text { increase } \\
2 \%\end{array}$ & $\begin{array}{l}\text { increase } \\
3 \%\end{array}$ & $\begin{array}{l}\text { increase } \\
5 \%\end{array}$ & Real & $\begin{array}{l}\text { increase } \\
0 \%\end{array}$ & $\begin{array}{l}\text { increase } \\
2 \%\end{array}$ & $\begin{array}{l}\text { increase } \\
3 \%\end{array}$ & $\begin{array}{l}\text { increase } \\
5 \%\end{array}$ \\
\hline province & 2756 & 2724 & 2780 & 2805 & 2860 & 0 & 0 & 0 & 0 & 0 \\
\hline
\end{tabular}

The sensitivity of limit photovoltaic and wind power in different resource of wind and photovoltaic is shown in Table 8 .

\begin{tabular}{|l|l|l|l|l|l|l|}
\hline \multirow{2}{*}{ Item } & Table 8 . The sensitivity in different load \\
\cline { 2 - 7 } & Use time of energy $(\mathrm{h})$ & Result $(\%)$ & Normal & Decrease $10 \%$ & Increase $10 \%$ \\
\hline Wind & 1454 & Decrease $10 \%$ & Increase $10 \%$ & 0 & 0 \\
\hline photovoltaic & 787 & 1308 & 1600 & 0 & 0 & 0 \\
\hline
\end{tabular}

According to the boundary conditions calculated in 2017 and the different wind power and photovoltaic power units installed scale, the clean energy dissipation capacity of the power grid in the next 2-3 years is estimated. The results are as follows:

If the wind and photoelectric installation exceeds 12 million KW, there may be a phenomenon of abandoning wind and photovoltaic power ( $2.25 \%$ of wind abandoning, $0.92 \%$ of discarded light); $3 \%$.

If the wind and photoelectric installation exceeds 14.5 million $\mathrm{KW}$, the abandon of wind and photovoltaic power will be

In 2018, it is expected to install wind and photovoltaic power of 9.6 million kilowatts, including wind power 3.7 million KW and photoelectric 5.9 million KW. According to the load ratio increased by $5 \%$ in 2018 and three areas such as proportion of installed wind power photoelectric calculation, there is no limit in the province.

New energy installed capacity in 2019 is expected to reach 11.25 million kilowatts; the wind increased by 1.15 million $\mathrm{KW}$, and increase ratio is $30 \%$. To this point, if installing in accordance with the three areas such as proportion, there will be abandoned discard wind phenomenon: abandon the wind $2.25 \%$, discard $0.92 \%$. The area $\mathrm{N}_{2}$ and $\mathrm{N}_{3}$ are obviously serious.

If installing more power units in $\mathrm{N}_{1}$ and improve the capacity of the transmission line, the abandonment of new energy will decrease in $\mathrm{N}_{2}$ and $\mathrm{N}_{3}$. The result is shown in Figure 4.

\begin{tabular}{|l|l|l|l|l|l|l|l|}
\hline $\mathbf{P}(\%)$ & N1 & N2 & N3 & P(\%) & N1 & N2 & N3 \\
\hline Wind abandon & $0.51 \%$ & $2.54 \%$ & $2.25 \%$ & Wind abandon & $0.1 \%$ & $0.27 \%$ & $0.23 \%$ \\
\hline PV abandon & $0.013 \%$ & $1.97 \%$ & $1.12 \%$ & PV abandon & $0 \%$ & $0.18 \%$ & $0.41 \%$ \\
\hline
\end{tabular}

Figure 4 . The change of the adopt of new energy

\section{Conclusions}

This paper studies the intermittent energy grid-connected power generation model simulation in yearly and monthly. In north China, there are a lot of heat-power combination generation units, which are used for winter heating demand. Heatpower combination generation units generally need to be "thermal power". Through the output of the heat, the power output the restriction of the winter heating load is very big, thus the load capacity is insufficient. In the certain provincial power grid, combining with the provincial power grid load and specific data unit information such as simulation, it is concluded that in the current wind power and photovoltaic power units installed, under the condition of new energy power generation can be given for the whole year, there is no abandon of the wind power phenomenon. For the operation state of the normal unit and the output of the start-stop status, it provides guidance for the management of the power grid. 
The data obtained in the project is the basic information of the power plant. To get the model input files, we first need to preprocess each file according to the year 8736 time-series statistics in the process. Through the visualization of the input data, some interesting conclusions about the load and the power of the landscape are obtained.

The output of the model is stored in Excel, with a total of 34 worksheets. The main ones are the variation of intermittent energy output over time. The results of this experiment are analyzed.

This project is currently using the commercial software GAMS [21] in the preparation of the program and simulation model, and at the time we use commercial solver CPLEX [22] to solve the model in parallel. Thus, there are some commercial software copyright and usage constraints in the procedure. Later, we will use open source solver SCIP [23] and the domestic software CMIP [16] with independent intellectual property rights to solve the model with parallel optimization, in terms of other energy generation (nuclear power, for example) to optimize the intermittent energy acceptance evaluation model.

\section{Acknowledgements}

This work is jointly supported by grant 2016YFB0200300 in the National Major Research High Performance Computing Program of China, and the State Key Program of National Natural Science Foundation of China (No. 91530324).

\section{References}

1. Y. Cao, C. Liu, Y. H. Huang. "Wind Power Accommodation Capability of Large-scale Interconnected Power Grid Based on Equivalent Aggregation Method,", High Voltage Engineering, pp 1-5, 2016

2. E. Ela, M. O. Malley. "Studying the Variability and Uncertainty Impacts of Variable Generation at Multiple Timescales [J]," IEEE Trans. Power System, vol 27, no. 3, pp 1324-1333 2012

3. H. Gao, X. J. Tong, H. B. Zhang. "Two Stages WCVaR Risk-profit Optimization Model under the Ellipsoidal Discrete Distribution and Application,” OPERATIONS RESEARCH AND MAMAGEMENT SCIENCE.

4. Y. W. Jeong, J. B. Park, S. H. Jang, et al. "A New Quantum-inspired Binary PSO: Application to Unit Commitment Problems for Power Systems [J],” IEEE Trans. Power System, vol 25, no. 3, pp 1486-1495, 2010

5. C. Liu, Y. Cao, Y. H. Huang. "An Annual Wind Power Planning Method Based on Time Sequential Simulations," Automation of Electric Power System, pp 1-6, 2014

6. C. Lowery, M. O. Malley. "Impact of Wind Forecast Error Statistics Upon Unit Commitment[J]," IEEE Trans. Sustainable Energy, vol 3, no. 4, pp 760-768, 2012

7. C. Liu, H. Wu, C. Z. Gao. "Study on Analysis Method of Accommodated Capacity for Wind Power," Power System Protection and Control, pp 1-4, 2014

8. D. W. Liu, Y. H. Huang, W. S. Wang, J. B. Guo. “Analysis on Provincial System Available Capability of Accommodating Wind Power Considering Peak Load Dispatch and Transmission Constraints," Automation of Electric Power System, vol 35, no. 22, pp 77-81, 2011

9. D. Li, X. L. Sun and K. Mckinnon. "An Exact Solution Method for Reliability Optimization in Complex Systems," Annals of Operations Research, pp 129-148, 2005.

10. Y. V. Makarov, P. V. Etingov, J. Ma, et al. "Incorporating Uncertainty of Wind Power Generation Forecast into Power System Operation, Dispatch, and Unit Commitment Procedures[J],” IEEE Trans. Sustainable Energy, vol 2, no. 4, pp 433-442, 2011

11. H. W. Ren, C. Y. Han, W. Pei, T. D. Guo. "Research on Distributed Generation Locating Based on Multi-objective Optimization Model," Power System Protection and Control.

12. X. L. Sun and D. Li. "Asymptotic Strong Duality for Bounded Integer Programming: A Logarithmic-Exponential Dual Formulation," Mathematics of Operational Research, 2000(4):625-644.

13. X. L. Sun and D. Li. "Optimality Condition and Branch and Bound Algorithm for Constrained Redundancy Optimization in Series Systems," Optimization and Engineering, no. 3, pp 53-65, 2002.

14. X. L. Sun, X. J. Zheng, and D. Li. "Recent Advances in Mathematical Programming with Semi-continuous Variables and Cardinality Constraint," Journal of the Operations Research Society of China, no. 3, pp 55-77, 2013

15. B. C. Ummels, M. Gibescu, E. Pelgrum, et al. "Impacts of Wind Power on Thermal Generation Unit Commitment and Dispatch [J],” IEEE Trans. Energy Conversion, vol 22, no. 1, pp 44-51, 2007

16. T. Q. Wang, F. Liu. "A Mixed Integer Model for Large-scale New Energy Medium-term Operation Problem,” pp 1-6, 2017

17. Z. Y. Xu, X. J. Luo, T. Niu. "Thermal Unit Commitment Scheme Considering Electricity Market and Energy-saving Dispatch," Automation of Electric Power System, vol 33, no. 22, pp 14-17 2009

18. L. Z. Zhang, N. Zhou, N. Wang. "Economic Comparison for Different Generation Schedulings with Large Scale Wind Power Connected Power System," Automation of Electric Power System, vol 35, no. 22, pp 105-110, 2011

19. X. J. Zheng, X. L. Sun, D. Li and X. T. Cui. "Lagrangian Decomposition and Mixed-integer Quadratic Programming Reformulations for Probabilistically Constrained Quadratic Programs," European Journal of Operational Research, pp 38-48, 2012

20. Z. Zhao, X. J. Tong and H. Gao. "Economic Dispatch of Wind Integrated Power System with A Conditional Risk Method,"

21. "GAMS Development Corp[EB/OL]," Available at https://www.gams.com, Last accessed on February 12, 2017. 
22. “CPLEX. Technical Report. IBM ILOG,” Available at http://www.ilog.com/products/cplex, Last accessed on August 10, 2017.

23. “SCIP [EB/OL],", Available at http://scip.zib.de, Last accessed on September 2, 2017.

Huifen Chen received her Ph.D. degree in Tsinghua University. Now she is a senior engineer of Henan electric power dispatching control center, State Grid HeNan Electric Power Company. Her current research interests include analysis and control technology of power system and power forecasting technology of new energy.

Yiming Zhang is a senior engineer of Henan electric power dispatching control center, State Grid HeNan Electric Power Company. His current research interests include analysis and control technology of power system and power forecasting technology of new energy.

Feng Yao received his M.S. degree in Xi'an Jiao Tong University, Xi'an, China, in 2006. Now he is a senior engineer of Henan electric power dispatching control center, State Grid HeNan Electric Power Company. His current research interest includes analysis and control technology of power system.

Zhice Yang a postgraduate of 2017 from Computer Network Information Center, Chinese Academy of Science, major in high performance computing, received the Bachelor degree from Beijing Jiaotong University.

Fang Liu received the Bachelor degree from Nanjing University, Nanjing, China, in 2005, and the Ph.D. degree from the Institute of Software, Chinese Academy of Science. Her research interests include high performance computing, and general-purpose computing on GPUs.

Yi Liu received his M.S. degree in Zheng Zhou University. Now he is a senior engineer of Henan electric power dispatching control center, State Grid HeNan Electric Power Company. His current research interest includes analysis and control technology of power system, and power forecasting technology of new energy.

Zhiheng Li received his M.S. degree in Huazhong University of Science and Technology. Now he is a senior engineer of Henan electric power dispatching control center, State Grid HeNan Electric Power Company. His current research interest includes operation analysis technology of power system.

Jinggang Wang received his M.S. degree in North China Electric Power University. Now he is a senior engineer of Henan electric power dispatching control center, State Grid HeNan Electric Power Company. His current research interest includes analysis technology of power system. 